\title{
Contemporary ICD Use in Patients with Heart Failure
}

\author{
Michael Spartalis (D) Kenzaburo Nakajima - David Zweiker • \\ Eleftherios Spartalis · Dimitrios C. Iliopoulos - Gerasimos Siasos
}

Received: May 3, 2021 / Published online: June 15, 2021

(C) The Author(s) 2021

\section{ABSTRACT}

Despite constant breakthroughs in heart failure (HF) therapy, the population of HF patients resume to grow and is linked to increased mortality and morbidity. Ventricular arrhythmias (VA) are one of the leading causes of mortality in HF subjects. Implantable cardioverter-defibrillators (ICDs) are currently the gold standard in treatment, preventing arrhythmic sudden cardiac death (SCD) episodes. However, the death rates related to HF remain elevated, as not all HF subjects benefit equally. Cardiac resynchronization therapy (CRT) has emerged as a novel approach for HF patients. These devices have been thoroughly investigated in major randomized controlled studies but continue to be underutilized in

M. Spartalis $(\bowtie) \cdot$ K. Nakajima · D. Zweiker Arrhythmia Unit, IRCCS San Raffaele Scientific Institute, San Raffaele University Hospital, Milan, Italy

e-mail: msparta@med.uoa.gr

M. Spartalis · E. Spartalis · D. C. Iliopoulos Laboratory of Experimental Surgery and Surgical Research 'N. S. Christeas', Medical School, National and Kapodistrian University of Athens, Athens, Greece

\section{G. Siasos}

1St Department of Cardiology, Medical School, Hippokration Hospital, National and Kapodistrian University of Athens, Athens, Greece various countries. This review discusses the use of ICD in HF populations on top of treatments.

Keywords: Heart failure; Implantable cardioverter-defibrillator; Ventricular arrhythmias; Cardiac resynchronization therapy; Sudden cardiac death

\section{Key Summary Points}

ICDs and CRTs are the cornerstone of current therapy of HF patients, reducing mortality and morbidity.

Despite these proven benefits, ICD and CRT therapies continue to be underutilized in various countries.

It is important to maintain medical education and conduct prospective randomized clinical trials in order to maximize patient selection and benefit.

Novel advances involve refining present treatments with leadless and subcutaneous devices. 


\section{DIGITAL FEATURES}

This article is published with digital features, including a summary slide, to facilitate understanding of the article. To view digital features for this article go to https://doi.org/10.6084/ m9.figshare.14685930.

\section{INTRODUCTION}

The European Society of Cardiology (ESC) guidelines categorize heart failure (HF) into HF with preserved ejection fraction (EF $>50 \%$, HFpEF), moderate EF (EF 40-49\%, HFmrEF), and reduced ejection fraction ( $\mathrm{EF}<40 \%$, HFrHF) [1]. The main etiology of death in HF patients is not only hemodynamic failure but life-threatening rhythm disturbances such as ventricular tachycardia (VT) and ventricular fibrillation (VF). Implantable cardioverter-defibrillators (ICDs) have become the standard of care in preventing arrhythmic sudden cardiac death (SCD), and cardiac resynchronization therapy (CRT) has evolved as an established treatment approach that improves a patient's quality of life and mortality [1].

Despite these proven benefits, the mortality and morbidity related to HF continue to be elevated [2]. Furthermore, ICDs therapy continues to be underutilized in various countries [2]. We will discuss the use of ICDs in HF with a primary focus on SCD prevention and CRT, including current literature and breakthrough advancements. This article is based on previously conducted studies and does not contain any studies with human participants or animals performed by any of the authors.

\section{HF AND SCD}

The knowledge regarding the susceptibility to SCD in HF is still scarce, hindering optimal risk stratification for the use of ICDs [2, 3]. Ventricular arrhythmias (VA) are frequent in HF patients and range in severity from asymptomatic premature ventricular contractions (PVCs) to sustained rhythm disturbances such as VT, ventricular fibrillation (VF), or SCD $[2,3]$.
The most often seen arrhythmia causing SCD in HF is VT degenerating into VF $[2,3]$.

SCD is defined as death resulting from sudden unexpected circulatory collapse caused by a cardiovascular cause $[2,3]$. SCD episode verification is generally difficult for clinical and research goals, affecting community-level estimates of SCD and resulting in variability in clinical trial reporting based on event definitions and ascertainment [2, 3]. Cardiovascular deaths are characterized as SCD when the collapse causing death is witnessed and occurs within $1 \mathrm{~h}$ of an alteration in health status, or when the death is not witnessed and occurs within the preceding $24 \mathrm{~h}[2,3]$. In addition, not all SCD are of arrhythmic etiology, and many are caused by pump failure or mechanical complications of myocardial infarction [2, 3]. One-third of cardiovascular deaths in $\mathrm{HF}$ patients is caused by gradual hemodynamic collapse, while the other two-thirds are caused either unexpectedly or in the context of progressing clinical HF [2, 3]. Overall mortality rates of SCD rise as the HF disease progresses, but the percentage of SCD deaths to total deaths decreases as the New York Heart Association (NYHA) functional class progresses [2, 3]. As HF advances, it is possible that more deaths are caused by pump failure rather than rhythm disturbances [2, 3]. MERIT-HF (Metoprolol CR/ XL Randomized Intervention Trial in Congestive Heart Failure) showed that the 1-year mortality rates for NYHA functional groups II, III, and IV were $6.3,10.5$, and $18.6 \%$, respectively. However, the percentage of SCD deaths to total deaths was 64, 59, and 33\%, respectively. Additionally, only $40 \%$ of SCD in HF are attributed to rhythm disturbances, a finding made mainly in HF patients after myocardial infarction $[2,3]$.

\section{DEVICE THERAPY FOR PRIMARY AND SECONDARY PREVENTION OF SCD}

HF subjects with $\mathrm{EF}<35 \%$ are at an elevated risk of SCD due to VA [3]. This risk is greater in subjects with past VA episodes [3]. In secondary prevention, where no reversible trigger, such as 
an acute myocardial infarction, could be detected, an ICD with a class IA recommendation is suggested (if survival is greater than 1 year with good functional status), according to ESC recommendations [1]. Although existing recommendations suggest ICD implantation in HF patients with an EF of less than 35\% after at least 3 months of optimal medical therapy, NYHA class II-IVa, and a projected lifespan of more than 1 year, there appears to be a difference in the positive impact of an ICD based on the underlying cardiac condition in primary prevention [1]. Subjects with ischemic cardiomyopathy (ICM) have an indication level of IA, while those without ICM have an indication level of IB [1]. The Sudden Cardiac Death in Heart Failure Trial (SCD-HeFT) and the Multicenter Automatic Defibrillator Implantation Trial II (MADIT-II) tried to determine the function of a transvenous defibrillator in primary prevention $[4,5]$. Both studies demonstrated an advantage in survival in subjects with an EF impairment $(30 \%$ in the MADIT-II study and $35 \%$ in the SCD-HeFT trial) $[4,5]$. In MADIT-II, which recruited subjects with ICM and a prior myocardial infarction, the transvenous defibrillator resulted in a $31 \%$ decrease in relative mortality over a 5 -year period $[4,5]$. On the other side, SCD-HeFT enrolled a combined group of patients with ICM and non-ICM (NICM) $[4,5]$. Subgroup studies revealed little disparity in the outcome of overall mortality decrease among ICM and NICM, suggesting that all patient populations benefited from the same impact $[4,5]$. In comparison, the most upto-date randomized Danish Study to Assess the Efficacy of ICDs in Patients with Non-ischemic Systolic Heart Failure on Mortality (DANISH) examined the function of primary prevention ICDs only in NICM and showed a large decrease in SCD in subjects with NICM and an EF of 35\% [6].

While a new study conducted by the European Heart Rhythm Association (EHRA) revealed that approximately $50 \%$ of clinicians reversed their existing practice of implanting a transvenous defibrillator in a NICM individual 4 months after the completion of the DANISH study, a meta-analysis demonstrated an advantage of primary preventive ICDs even in terms of overall mortality $[7,8]$. Optimizing patient selection of NICM patients could be the best approach to enhance the value of a transvenous defibrillator [7, 8]. Subgroup examinations of the DANISH study revealed that patients less than 70 years old or those with mild HF (as determined by lower NT-proBNP concentrations) did not experience a decrease in all-cause mortality [7-9]. Such findings suggest that relying solely on the EF to determine when a patient dies from hemodynamic collapse or VA could be inadequate [10-12]. The Seattle Heart Failure Model integrates a variety of risk factors, including age and laboratory criteria for $\mathrm{HF}$ prognosis, and can be an alternative strategy approach for optimal ICD patient selection [13]. Another interesting approach is to evaluate the myocardial substrate that could be proarrhythmogenic [13]. On cardiac magnetic resonance imaging (MRI), late gadolinium enhancement (LGE) highlights regions of myocardial fibrosis, and studies indicate that patients with LGE are at an elevated risk of SCD and VA [13, 14]. In subjects with dilated cardiomyopathy (DCM) and an EF of $40 \%$, mid-wall LGE was correlated with a significant elevation in the risk of SCD [15]. Electroanatomical mapping (EAM) is a relatively popular technique for invasively examining myocardial scarring [16]. Local electrical properties may be used to distinguish scar tissue from healthy myocardium during an electrophysiological (EP) examination [16]. While both imaging modalities show tremendous potential, their utility must be evaluated prospectively in randomized controlled studies $[15,16]$. Numerous other indicators of elevated arrhythmia risk, including genetic analysis, circulating biochemical markers, and non-invasive EP analysis, can be integrated into the ICD decision-making method $[15,16]$.

The decrease of SCD associated with an ICD in this population might not be attributed solely to an excess of non-arrhythmogenic fatalities but rather to device-related complications and morbidity [17]. As a result, further research and development in the area of device technologies are critical [17]. The subcutaneous ICD (S-ICD) is an innovative ICD intended to reduce the incidence and related morbidity and mortality linked to infection [17]. Infection is 
Table 1 Landmark trials of defibrillators for the prevention of sudden cardiac death $[3-7,31,58-61]$

\begin{tabular}{|c|c|c|c|c|c|}
\hline Study & $\begin{array}{l}\text { SCD } \\
\text { prevention }\end{array}$ & $\begin{array}{l}\text { Number } \\
\text { of } \\
\text { subjects }\end{array}$ & Population & Study arms & Hazard ratio \\
\hline AVID & Secondary & 1016 & $\begin{array}{l}\text { Resuscitated VF, cardioverted VT, VT and syncope } \\
\text { or VT and EF } \leq 40 \% \text { and hemodynamic } \\
\text { compromise }\end{array}$ & ICD versus class III AAD & $\begin{array}{l}0.62 \\
\quad(P<0.02)\end{array}$ \\
\hline $\mathrm{CASH}$ & Secondary & 288 & Resuscitated cardiac arrest from documented VA & $\begin{array}{l}\text { ICD versus amiodarone } \\
\text { versus metoprolol }\end{array}$ & $\begin{array}{l}0.77 \\
\quad(P=\mathrm{NS})\end{array}$ \\
\hline CIDS & Secondary & 659 & Resuscitated VF or VT or unmonitored syncope & ICD versus amiodarone & $\begin{array}{l}0.80 \\
\quad(P=\mathrm{NS})\end{array}$ \\
\hline MADIT & Primary & 196 & $\begin{array}{l}\text { Prior MI and } \mathrm{EF} \leq 35 \% \text { and NSVT and inducible } \\
\text { sustained VT or VF on EP study }(>3 \text { weeks } \\
\text { post-MI, }>2 \text { months post-CABG, }>3 \text { months } \\
\text { post-PCI) }\end{array}$ & $\begin{array}{l}\text { ICD versus conventional } \\
\text { medical therapy }\end{array}$ & $\begin{array}{l}0.46 \\
\quad(P=0.009)\end{array}$ \\
\hline MUSTT & Primary & 704 & $\begin{array}{l}\text { CAD and } \mathrm{EF} \leq 40 \% \text { and asymptomatic NSVT } \\
\text { and Inducible sustained VA ( } 34 \text { days post-MI or } \\
\text { PCI) }\end{array}$ & $\begin{array}{l}\text { EP-guided therapy with } \\
\text { AADs or ICD or no } \\
\text { AADs }\end{array}$ & $\begin{array}{l}0.40 \\
\quad(P<0.001)\end{array}$ \\
\hline MADIT II & Primary & 1232 & $\begin{array}{l}\text { Prior } \mathrm{MI} \text { and } \mathrm{EF} \leq 30 \% \text { ( }>1 \text { month post- } \\
\quad \mathrm{MI},>3 \text { months post-PCI) }\end{array}$ & $\begin{array}{l}\text { ICD versus conventional } \\
\text { medical therapy }\end{array}$ & $\begin{array}{l}0.69 \\
\qquad(P=0.02)\end{array}$ \\
\hline DEFINITE & Primary & 458 & NICM EF $<36 \%$ and PVC or NSVT & $\begin{array}{l}\text { ICD and standard } \\
\text { medical therapy versus } \\
\text { medical therapy alone }\end{array}$ & $\begin{array}{l}0.65 \\
\qquad(P=0.08)\end{array}$ \\
\hline SCDHeFT & Primary & 2521 & NYHA II-III and EF $\leq 35 \%$ ( $>3$ months HF) & $\begin{array}{l}\text { ICD versus amiodarone } \\
\text { versus placebo }\end{array}$ & $\begin{array}{l}0.77 \\
\quad(P=0.007)\end{array}$ \\
\hline DANISH & Primary & 1116 & $\begin{array}{l}\text { NICM EF } \leq 35 \% \text { and NYHA II or III, or IV if } \\
\text { CRT was scheduled and NT-pro } \\
\text { BNP }>200 \mathrm{pg} / \mathrm{ml}\end{array}$ & $\begin{array}{l}\text { ICD versus standard care } \\
\text { CRT received in } 58 \% \\
\text { in both groups }\end{array}$ & $\begin{array}{l}0.87 \\
\quad(P=0.28)\end{array}$ \\
\hline
\end{tabular}

$S C D$ sudden cardiac death, $A V I D$ Antiarrhythmics Versus Implantable Defibrillator, $V F$ ventricular fibrillation, $V T$ ventricular tachycardia, $E F$ ejection fraction, $I C D$ implantable cardioverter defibrillator, $A A D$ antiarrhythmic drug, $C A S H$ Cardiac Arrest Survival in Hamburg, $V A$ ventricular arrhythmias, CIDS Canadian Implantable Defibrillator Study, MADIT Multicenter Automatic Defibrillator Implantation Trial, $M I$ myocardial infarction, $N S V T$ non-sustained ventricular tachycardia, $E P$ electrophysiological, $C A B G$ coronary artery bypass graft, $P C I$ percutaneous coronary intervention, $M U S T T$ Multicenter Unsustained Tachycardia Trial, $C A D$ coronary artery disease, MADIT-II Multicenter Automatic Defibrillator Implantation II Trial, DEFINITE Defibrillators in Non-Ischemic Cardiomyopathy Treatment Evaluation, NICM non-ischemic cardiomyopathy, PVC premature ventricular complex, SCD-HeFT Sudden Cardiac Death in Heart Failure Trial, NYHA New York Heart Association, HF heart failure, DANISH Danish Study to Assess the Efficacy of ICDs in Patients With Nonischemic Systolic Heart Failure on Mortality, CRT cardiac resynchronization therapy, BNP brain natriuretic peptide

the most significant lifelong threat related to transvenous devices [17]. In an S-ICD, the generator is situated on the left mid-axillary position, between the anterior serratus and latissimus dorsi muscles [17]. The lead is tunneled beneath the skin into the xiphoid process 
and then progressed cranially alongside the sternum [17]. The PRAETORIAN trial showed that S-ICD avoids major complications associated with the transvenous ICD, including serious infection and lead-related complications, establishing S-ICD as an appropriate and potentially attractive option for primary and secondary prevention in subjects who do not require pacing [18]. Recent ESC recommendations propose that, in the absence of contraindications, an S-ICD with a class IIa sign can be used instead of a transvenous ICD [19]. An S-ICD is not appropriate for subjects that need pacing, cardiac resynchronization therapy, and overdrive pacing $[18,19]$. Resolving the majority of these issues seems to be achievable in the near future when a mixture of S-ICD and a leadless pacemaker would reach clinical trials [18]. Additionally, subjects must perform preprocedure sensing vector testing to achieve sufficient sensing of the QRS complex and T wave in order to prevent both undersensing or oversensing of the $T$ wave [18]. At least one of the three sensing vectors must provide adequate sensing in the supine and sitting or standing positions [18]. Table 1 summarizes the landmark trials of defibrillators for the prevention of SCD.

\section{CRT DEFIBRILLATOR}

CRT has essentially altered how HF patients are handled [20]. Left ventricular dysfunction often leads to ventricular conduction disorder, which, consequently, causes electrical and mechanical dyssynchrony of the ventricle, disrupting the ventricle's hemodynamics even more [20]. The aim of biventricular pacing is to break this vicious cycle [20].

CRT is recommended in subjects with NYHA II-IVa status HF after 3 months of optimum medical therapy, EF of $35 \%$, and QRS complex of $130 \mathrm{~ms}$ [20]. The recommendation is based on the findings of two major trials investigating the impact of CRT in subjects with advanced HF (mainly NYHA III) with QRS complex of $120 \mathrm{~ms}$; the Comparison of Medical Therapy, Pacing, and Defibrillation in Heart Failure (COMPANION) and the Cardiac Resynchronization-
Heart Failure (CARE-HF) trials [21, 22]. These trials established that biventricular pacing decreased total mortality in this population by up to $36 \%$, a finding that was eventually validated by databases and meta-analyses [23-25]. CRT has also been investigated in people with minor HF symptomatology (NYHA II) [26]. The MADIT-CRT trial examined HF subjects with EF less than 30\%, NYHA score of I-II, and a QRS complex greater than $130 \mathrm{~ms}$ [26]. Total mortality was $34 \%$ lesser in the CRT population relative to the conservatively treated group [26]. This result is corroborated by evidence from the Resynchronization-Defibrillation for Ambulatory Heart Failure (RAFT) study, which demonstrated that CRT decreases overall mortality by $25 \%$ in subjects with an EF of $30 \%$, a QRS complex greater than $120 \mathrm{~ms}$, and NYHA II-III [27].

There is inadequate evidence from the MADIT-CRT and RAFT studies to suggest CRT in subjects with NYHA class I $[26,27]$. Although CRT devices minimize mortality in appropriately chosen individuals, they have little advantage and can inflict damage if they are used in incorrect subjects [28]. The EchoCRT study showed little advantage and an enhanced risk of death when a CRT system is inserted in individuals with a narrow QRS (even though mechanical dyssynchrony of the ventricle was validated by echocardiogram) [27].

CRT system implant in subjects with left bundle branch block (LBBB) is classified as a class I recommendation (IA if the QRS duration is greater than $150 \mathrm{~ms}$, IB if the QRS width is 130-149 ms), while non-LBBB cases are classified as a class II indication [29, 30]. LBBB subjects seem to have a more serious form of left ventricle electrical dyssynchrony than those without LBBB and are thus more likely to gain from CRT $[29,30]$. A subgroup study in the MADIT-CRT study demonstrated that only LBBB individuals benefited from resynchronization therapy in terms of HF event-free survival $[26,27,31]$. This result is corroborated by a meta-analysis of these studies, which concluded that CRT has little effect in non-LBBB individuals [25].

The overwhelming majority of CRT studies excluded subjects with atrial fibrillation (AF), 
notwithstanding the possibility that $\mathrm{AF}$ and $\mathrm{HF}$ often co-exist and $\mathrm{HF}$ subjects with $\mathrm{AF}$ had a poorer prognosis $[32,33]$. Due to the rapid, erratic conduction, AF often hinders the benefit of resynchronization therapy in comparison to sinus rhythm [34]. When AF though is disrupted by atrioventricular junction ablation, the advantage of resynchronization therapy is comparable to that of individuals without AF in several meta-analyses [35, 36].

On the other hand, it is important to keep in mind that up to one-third of individuals treated with resynchronization therapy do not experience a long-term gain (non-responders) [37, 38]. There is, however, no universally accepted concept of response and non-response [20,39]. Although several studies utilize clinical criteria (mortality, HF hospital admissions, and NYHA status) [20, 39], many utilize echocardiographic measures (improved EF, decreased end-systolic volume) or a mixture of the two [40]. Occasionally, a difference in clinical and echocardiographic responses occurs [41]. Individuals with ICM do not have a good echocardiographic response to resynchronization therapy $[42,43]$. Nevertheless, the value of resynchronization therapy was not contingent on the underlying heart disease in the landmark studies (CARE-HF and COMPANION) [21, 22]. On the opposite, since ICM subjects have poorer survival rates and a greater absolute incidence of new episodes, their overall risk reduction could be much greater, resulting in a much lower amount needed to treat [44].

The absence of marked change in EF and health condition following resynchronization therapy could cause clinicians to overlook resynchronization therapy as a viable method of reducing mortality and morbidity, resulting in a reduction in the overall utilization percentages [37]. Physicians often overlook in such instances that HF is a relentlessly progressing, chronic condition and that stabilization of its path indicates a major advantage of CRT for this susceptible subject group.

Certain individuals profit enormously from CRT and can even achieve normal left ventricular function (super-responders) [37]. While echocardiographic evaluation of ventricular dyssynchrony is not a good predictor of response, pre-procedural imaging can become more critical in deciding the optimal location for the left ventricular lead [45-48]. This may be accomplished by CMR and computed tomographic imaging of the coronary sinus to assess LGE or by speckle tracking echocardiography to measure strain and late mechanical activation sites [45-48]. It is critical to position the lead at the location with the latest activation, if necessary, in order to have a better degree of resynchronization [49]. Surgical epicardial lead positioning is currently restricted by its invasive existence and the possibility of scarring, which can result in the lead performing suboptimal over time [49].

Additionally, optimal application programming by cardiac device specialists and troubleshooting post-procedure and during followup is critical to maximizing gain [50]. Optimizing systems regularly after implantation has not been found to be clinically beneficial, but it could be applicable to non-responders, negative responders, and those undergoing clinical episodes and complications [51]. Additionally, device-based applications for optimizing CRT response, such as AdaptivCRT or SyncAV, can gain prominence in the future [52-54]. Quadripolar left ventricular leads, which were introduced only recently, have greater programming versatility by allowing for more pacing vector variations while eliminating phrenic capture and apical pacing [52-54].

Along with biventricular stimulation, additional pacing strategies are being investigated that may increase the performance of HF individuals $[55,56]$. His-bundle pacing has been found to be an effective alternative for subjects with a need of constant ventricular pacing when used in conjunction with bradycardia indications [55]. His-bundle pacing in HF individuals is currently being examined in a number of studies (HOPE-HF trial, His-SYNC trial) $[55,56]$. His-bundle pacing is considered a viable option for individuals undergoing CRT who have undesirable coronary sinus anatomy $[55,56]$. The potential role of His-bundle pacing in non-responders, though, is still unknown $[55,56]$. The His-SYNC trial concluded that subjects receiving His-bundle pacing on top of treatments showed improved electrical 
resynchronization and a tendency toward greater echocardiographic response than standard resynchronization therapy [57].

\section{NOVEL CONCEPTS IN DEFIBRILLATOR THERAPY IN HF}

In a post hoc study of SCDHeFT, it was discovered that ICD shocks, whether appropriate or not, were correlated with a lower rate of survival in ICD patients [58-60]. Much research has shown that shocks can be minimized by proper programming, which allows for longer detections and durations before shock initiation [60]. Furthermore, a randomized trial (MADIT-RIT) demonstrated that such programming is correlated with increased patient survival [60]. As a result, strategic programming is highly advised [60].

Wearable cardioverter-defibrillators were newly launched as a bridge to ICD or as a bridge to decision [61]. Wearable cardioverter-defibrillators can be beneficial in individuals with elevated SCD risk but do not want to undergo ICD implantation [61]. These devices have been demonstrated to be as effective as ICD in terminating VA [61]. However, they are hindered by their lack of stimulation and their failure to provide antitachycardia pacing [61]. In the early post-myocardial infarction era, these defibrillators greatly reduced the risk of arrhythmic SCD in individuals with $\mathrm{EF}$ of $35 \%$, as determined by the VEST (Vest Prevention of Early Sudden Death Trial) [61]. Due to initial enrollment difficulties, the study's goal sample size was limited, and the primary endpoint was revised from all-cause to arrhythmic SCD, raising some bias issues [61]. Additionally, adherence with the wearable defibrillators was lower than predicted, which may have an effect on the power estimate [61].

Intravascular lead complications have resulted in the leadless systems boom [61]. While their usage in HF individuals is currently minimal, single leadless pacing devices (Nanostim from St Jude Medical, Inc and Micra Transcatheter Pacing System from Medtronic, Inc) could have potential use in these patients, especially when utilized together with subcutaneous devices [17, 18, 61]. However, multicomponent leadless devices are now being used in HF subjects $[17,18,61]$. The WiSE-CRT research (Wireless Stimulation Endocardially for CRT) evaluated the efficacy of leadless endocardial left ventricular pacing using ultrasound in CRT individuals [61]. A subcutaneous pulse generator and a tiny receiver electrode are inserted in the left ventricular endocardium as part of the multicomponent system [61]. The results from the study were positive, but the research was prematurely terminated for safety concerns [61]. The SELECT-LV research (Safety and Performance of Electrodes Implanted in the Left Ventricle) demonstrated both efficacy and potential clinical progress utilizing this method [61]. This method, though, is not completely lead-free, since it requires the existence of RV defibrillation lead [61].

ICDs, today, allow remote data collection via data transmission to a computer, which then transmits data to an encrypted server and then to the responsible physician [61]. The details presented relate to both patient management and system operation monitoring [61]. The number of metrics that may be tracked continues to expand [61]. It also incorporates information regarding heart rate, patient activity, the percentage of biventricular stimulation, the frequency of rhythm disturbances, alterations in thoracic impedance as an indicator of pulmonary congestion, and heart rate variability [61]. The expectation is that this type of surveillance will predict preclinical symptoms of acute HF, leading to therapies that will minimize hospitalization and enhance the quality of life [61].

Device features and, more specifically, lead warnings can also be monitored remotely $[61,62]$. This is critical for devices to resume providing effective life-sustaining treatments $[61,62]$. Numerous reported investigations advocate the usage of remote monitoring for lead failure diagnosis [61, 62]. As such, the Heart Rhythm Society and the Canadian Heart Rhythm Society have issued consensus statements endorsing the importance of remote monitoring in diagnosing lead failure and monitoring at-risk leads $[61,62]$. 


\section{CONCLUSIONS}

ICDs and CRTs are critical components of current HF therapy, significantly lowering mortality and morbidity in the community. Continuous medical education is critical for optimizing patient selection and benefit based on pathophysiological mechanisms, epidemiology, clinical study outcomes, and advanced technology. Current and prospective research and scientific advancements hope to enhance individuals' prognoses further. Only by joint efforts of all parties, such as cardiologists, primary care physicians, and, progressively, the patient, would we be able to advance science and research and better establish strategies for improving the survival rate of HF individuals.

\section{ACKNOWLEDGEMENTS}

Funding. No funding or sponsorship was received for this study or publication of this article.

Authorship. All named authors meet the International Committee of Medical Journal Editors (ICMJE) criteria for authorship for this article, take responsibility for the integrity of the work as a whole, and have given their approval for this version to be published.

Author Contributions. All authors contributed to the study conception and design. Material preparation, data collection, and analysis were performed by Dr. Michael Spartalis, Dr. Kenzaburo Nakajima, Dr. David Zweiker, Dr. Eleftherios Spartalis, Prof. Dimitrios Iliopoulos and Prof. Gerasimos Siasos. The first draft of the manuscript was written by Dr. Michael Spartalis, and all authors commented on previous versions of the manuscript. All authors read and approved the final manuscript.

Disclosures. Dr. Michael Spartalis is supported by a scholarship from the Hellenic Society of Cardiology (Athens, Greece). Dr. Kenzaburo Nakajima, Dr. David Zweiker, Dr. Eleftherios Spartalis, Prof. Dimitrios Iliopoulos and Prof. Gerasimos Siasos have nothing to disclose.

Compliance with Ethics Guidelines. This article is based on previously conducted studies and does not contain any studies with human participants or animals performed by any of the authors.

Data Availability. Data sharing is not applicable to this article, as no datasets were generated or analyzed during the current study.

Open Access. This article is licensed under a Creative Commons Attribution-NonCommercial 4.0 International License, which permits any non-commercial use, sharing, adaptation, distribution and reproduction in any medium or format, as long as you give appropriate credit to the original author(s) and the source, provide a link to the Creative Commons licence, and indicate if changes were made. The images or other third party material in this article are included in the article's Creative Commons licence, unless indicated otherwise in a credit line to the material. If material is not included in the article's Creative Commons licence and your intended use is not permitted by statutory regulation or exceeds the permitted use, you will need to obtain permission directly from the copyright holder. To view a copy of this licence, visit http://creativecommons.org/licenses/by$\mathrm{nc} / 4.0 /$.

\section{REFERENCES}

1. Ponikowski P, Voors AA, Anker SD, et al. ESC Guidelines for the diagnosis and treatment of acute and chronic heart failure: the task force for the diagnosis and treatment of acute and chronic heart failure of the European Society of Cardiology (ESC). Developed with the special contribution of the Heart Failure Association (HFA) of the ESC. Eur J Heart Failure. 2016;18:891-975.

2. Dickstein K, Normand C, Auricchio A, et al. CRT Survey II: a European Society of Cardiology survey of cardiac resynchronisation therapy in 11088 patients-who is doing what to whom and how? Eur J Heart Failure. 2018;20:1039-51. 
3. Connolly SJ, Hallstrom AP, Cappato R, et al. Metaanalysis of the implantable cardioverter defibrillator secondary prevention trials. AVID, CASH and CIDS studies Antiarrhythmics vs Implantable Defibrillator study. Cardiac Arrest Study Hamburg. Canadian Implantable Defibrillator Study. Eur Heart J. 2000;21:2071-8. https://doi.org/10.1053/ euhj.2000.2476.

4. Bardy GH, Lee KL, Mark DB, et al. Amiodarone or an implantable cardioverter-defibrillator for congestive heart failure. N Engl J Med. 2005;352:225-37. https://doi.org/10.1056/NEJMoa043399.

5. Moss AJ, Zareba W, Hall WJ, et al. Prophylactic implantation of a defibrillator in patients with myocardial infarction and reduced ejection fraction. N Engl J Med. 2002;346:877-83. https://doi. org/10.1056/NEJMoa013474.

6. Kober L, Thune JJ, Nielsen JC, et al. Defibrillator implantation in patients with nonischemic systolic heart failure. N Engl J Med. 2016;375:1221-30. https://doi.org/10.1056/NEJMoa1608029.

7. Haugaa $\mathrm{KH}$, Tilz $\mathrm{R}$, Boveda $\mathrm{S}$, et al. Implantable cardioverter defibrillator use for primary prevention in ischaemic and non-ischaemic heart disease-indications in the post-DANISH trial era: results of the European Heart Rhythm Association survey. Europace. 2017;19:660-4. https://doi. org/10.1093/europace/eux089.

8. Desai AS, Fang JC, Maisel WH, Baughman KL. Implantable defibrillators for the prevention of mortality in patients with nonischemic cardiomyopathy: a meta-analysis of randomized controlled trials. JAMA. 2004;292:2874-9. https://doi.org/10. 1001/jama.292.23.2874.

9. Elming MB, Nielsen JC, Haarbo J, et al. Age and outcomes of primary prevention implantable cardioverte-defibrillators in patients with nonischemic systolic heart failure. Circulation. 2017;136: 1772-80.

10. Gorgels AP, Gijsbers C, de Vreede-Swagemakers J, Lousberg A, Wellens HJ. Out-of-hospital cardiac arrest-the relevance of heart failure. The Maastricht Circulatory Arrest Registry. Eur Heart J. 2003;24: 1204-9. $\quad$ https://doi.org/10.1016/S0195668X(03)00191-X.

11. Stecker EC, Vickers C, Waltz J, et al. Populationbased analysis of sudden cardiac death with and without left ventricular systolic dysfunction: twoyear findings from the Oregon Sudden Unexpected Death Study. J Am Coll Cardiol. 2006;47:1161-6. https://doi.org/10.1016/j.jacc.2005.11.045.

12. Levy WC, Lee KL, Hellkamp AS, et al. Maximizing survival benefit with primary prevention implantable cardioverter-defibrillator therapy in a heart failure population. Circulation. 2009;120: 835-42. https://doi.org/10.1161/ CIRCULATIONAHA.108.816884.

13. Moon JC, Reed E, Sheppard MN, et al. The histologic basis of late gadolinium enhancement cardiovascular magnetic resonance in hypertrophic cardiomyopathy. J Am Coll Cardiol. 2004;43: 2260-4. https://doi.org/10.1016/j.jacc.2004.03.035.

14. Kuruvilla S, Adenaw N, Katwal AB, Lipinski MJ, Kramer CM, Salerno M. Late gadolinium enhancement on cardiac magnetic resonance predicts adverse cardiovascular outcomes in nonischemic cardiomyopathy: a systematic review and metaanalysis. Circ Cardiovasc Imag. 2014;7:250-8.

15. Halliday BP, Gulati A, Ali A, et al. Association between midwall late gadolinium enhancement and sudden cardiac death in patients with dilated cardiomyopathy and mild and moderate left ventricular systolic dysfunction. Circulation. 2017;135: 2106-15.

16. Sasaki T, Miller CF, Hansford R, et al. Impact of nonischemic scar features on local ventricular electrograms and scar-related ventricular tachycardia circuits in patients with nonischemic cardiomyopathy. Circ Arrhythmia Electrophysiol. 2013;6:1139-47. https://doi.org/10.1161/CIRCEP. 113.000159 .

17. Brouwer TF, Yilmaz D, Lindeboom R, et al. Longterm clinical outcomes of subcutaneous versus transvenous implantable defibrillator therapy. J Am Coll Cardiol. 2016;68:2047-55. https://doi.org/10. 1016/j.jacc.2016.08.044.

18. Knops RE, Olde Nordkamp LRA, Delnoy PHM, et al. Subcutaneous or Transvenous Defibrillator Therapy. N Engl J Med. 2020;383(6):526-36. https://doi. org/10.1056/NEJMoa1915932 (PMID: 32757521).

19. Breitenstein A, Steffel J. Devices in heart failure patients-Who benefits from ICD and CRT? Front Cardiovasc Med. 2019;6:111. https://doi.org/10. 3389/fcvm.2019.00111.

20. Young JB, Abraham WT, Smith AL, et al. Combined cardiac resynchronization and implantable cardioversion defibrillation in advanced chronic heart failure: the MIRACLE ICD trial. JAMA. 2003;289: 2685-94. https://doi.org/10.1001/jama.289.20. 2685.

21. Bristow MR, Saxon LA, Boehmer J, et al. Cardiacresynchronization therapy with or without an implantable defibrillator in advanced chronic heart failure. N Engl J Med. 2004;350:2140-50. https:// doi.org/10.1056/NEJMoa032423. 
22. Cleland JG, Daubert JC, Erdmann E, et al. The effect of cardiac resynchronization on morbidity and mortality in heart failure. N Engl J Med. 2005;352: 1539-49. https://doi.org/10.1056/NEJMoa050496.

23. Bilchick KC, Kamath S, DiMarco JP, Stukenborg GJ. Bundle-branch block morphology and other predictors of outcome after cardiac resynchronization therapy in Medicare patients. Circulation. 2010;122:2022-30.

24. Gold MR, Thebault C, Linde C, et al. Effect of QRS duration and morphology on cardiac resynchronization therapy outcomes in mild heart failure: results from the resynchronization reverses remodeling in systolic left ventricular dysfunction (REVERSE) study. Circulation. 2012;126:822-9.

25. Cunnington C, Kwok CS, Satchithananda DK, et al. Cardiac resynchronisation therapy is not associated with a reduction in mortality or heart failure hospitalisation in patients with non-left bundle branch block QRS morphology: meta-analysis of randomised controlled trials. Heart. 2015;101: 1456-62. https://doi.org/10.1136/heartjnl-2014306811.

26. Moss AJ, Hall WJ, Cannom DS, et al. Cardiacresynchronization therapy for the prevention of heart-failure events. N Engl J Med. 2009;361: 1329-38. https://doi.org/10.1056/NEJMoa0906431.

27. Tang AS, Wells GA, Talajic M, et al. Cardiac-resynchronization therapy for mild-to-moderate heart failure. N Engl J Med. 2010;363:2385-95.

28. Ruschitzka F, Abraham WT, Singh JP, et al. Cardiacresynchronization therapy in heart failure with a narrow QRS complex. N Engl J Med. 2013;369: 1395-405. NEJMoa1306687.

29. Haghjoo M, Bagherzadeh A, Farahani MM, Haghighi ZO, Sadr-Ameli MA. Significance of QRS morphology in determining the prevalence of mechanical dyssynchrony in heart failure patients eligible for cardiac resynchronization: particular focus on patients with right bundle branch block with and without coexistent left-sided conduction defects. Europace. 2008;10:566-71. https://doi.org/ 10.1093/europace/eun081.

30. Yu CM, Fung JW, Chan CK, et al. Comparison of efficacy of reverse remodeling and clinical improvement for relatively narrow and wide QRS complexes after cardiac resynchronization therapy for heart failure. J Cardiovasc Electrophysiol. 2004;15:1058-65. https://doi.org/10.1046/j.15408167.2004.03648.x.

31. Zareba W, Klein H, Cygankiewicz I, et al. Effectiveness of cardiac resynchronization therapy by qrs morphology in the multicenter automatic defibrillator implantation trial-cardiac resynchronization therapy (MADIT-CRT). Circulation. 2011;123: 1061-72. https://doi.org/10.1161/ CIRCULATIONAHA.110.960898.

32. Olsson LG, Swedberg K, Ducharme A, et al. Atrial fibrillation and risk of clinical events in chronic heart failure with and without left ventricular systolic dysfunction: results from the Candesartan in Heart Failure-assessment of reduction in mortality and morbidity (CHARM) program. J Am Coll Cardiol. 2006;47:1997-2004. https://doi.org/10.1016/j. jacc.2006.01.060.

33. Trulock KM, Narayan SM, Piccini JP. Rhythm control in heart failure patients with atrial fibrillation: contemporary challenges including the role of ablation. J Am Coll Cardiol. 2014;64:710-21. https://doi.org/10.1016/j.jacc.2014.06.1169.

34. Wilton SB, Leung AA, Ghali WA, Faris P, Exner DV. Outcomes of cardiac resynchronization therapy in patients with versus those without atrial fibrillation: a systematic review and meta-analysis. Heart Rhythm. 2011;8:1088-94. https://doi.org/10.1016/ j.hrthm.2011.02.014.

35. Gasparini M, Auricchio A, Metra M, et al. Longterm survival in patients undergoing cardiac resynchronization therapy: the importance of performing atrio-ventricular junction ablation in patients with permanent atrial fibrillation. Eur Heart J. 2008;29:1644-52. https://doi.org/10.1093/ eurheartj/ehn133.

36. Ganesan AN, Brooks AG, Roberts-Thomson KC, Lau DH, Kalman JM, Sanders P. Role of AV nodal ablation in cardiac resynchronization in patients with coexistent atrial fibrillation and heart failure a systematic review. J Am Coll Cardiol. 2012;59:719-26. https://doi.org/10.1016/j.jacc.2011.10.891.

37. Steffel J, Ruschitzka F. Superresponse to cardiac resynchronization therapy. Circulation. 2014;130: 87-90. https://doi.org/10.1161/ CIRCULATIONAHA.113.006124.

38. Versteeg H, Schiffer AA, Widdershoven JW, Meine MM, Doevendans PA, Pedersen SS. Response to cardiac resynchronization therapy: is it time to expand the criteria? Pacing Clin Electrophysiol. 2009;32:1247-56. https://doi.org/10.1111/j.15408159.2009.02505.x.

39. Packer M. Proposal for a new clinical end point to evaluate the efficacy of drugs and devices in the treatment of chronic heart failure. J Cardiac Failure. 2001;7:176-82. https://doi.org/10.1054/jcaf.2001. 25652 . 
40. Pitzalis MV, Iacoviello M, Romito R, et al. Cardiac resynchronization therapy tailored by echocardiographic evaluation of ventricular asynchrony. J Am Coll Cardiol. 2002;40:1615-22. https://doi.org/10. 1016/S0735-1097(02)02337-9.

41. Bleeker GB, Bax JJ, Fung JW, et al. Clinical versus echocardiographic parameters to assess response to cardiac resynchronization therapy. Am J Cardiol. 2006;97:260-3. https://doi.org/10.1016/j.amjcard. 2005.08.030.

42. Adelstein EC, Saba S. Scar burden by myocardial perfusion imaging predicts echocardiographic response to cardiac resynchronization therapy in ischemic cardiomyopathy. Am Heart J. 2007;153: 105-12. https://doi.org/10.1016/j.ahj.2006.10.015.

43. Gasparini M, Mantica M, Galimberti P, et al. Is the outcome of cardiac resynchronization therapy related to the underlying etiology? Pacing Clin Electrophysiol. 2003;26:175-80. https://doi.org/10. 1046/j.1460-9592.2003.00011.x.

44. Wikstrom G, Blomstrom-Lundqvist C, Andren B, et al. The effects of aetiology on outcome in patients treated with cardiac resynchronization therapy in the CARE-HF trial. Eur Heart J. 2009;30: 782-8. https://doi.org/10.1093/eurheartj/ehn577.

45. Chung ES, Leon AR, Tavazzi L, et al. Results of the predictors of response to CRT (PROSPECT) trial. Circulation. 2008;117:2608-16.

46. Khan FZ, Virdee MS, Palmer CR, et al. Targeted left ventricular lead placement to guide cardiac resynchronization therapy: the TARGET study: a randomized, controlled trial. J Am Coll Cardiol. 2012;59:1509-18. https://doi.org/10.1016/j.jacc. 2011.12.030.

47. Saba S, Marek J, Schwartzman D, et al. Echocardiography-guided left ventricular lead placement for cardiac resynchronization therapy: results of the Speckle Tracking Assisted Resynchronization Therapy for Electrode Region trial. Circ Heart Failure. 2013;6:427-34. https://doi.org/10.1161/ CIRCHEARTFAILURE.112.000078.

48. Leyva F, Foley PW, Chalil S, et al. Cardiac resynchronization therapy guided by late gadoliniumenhancement cardiovascular magnetic resonance. J Cardiovasc Magn Resonance. 2011;13:29. https:// doi.org/10.1186/1532-429X-13-29.

49. Roubicek T, Wichterle D, Kucera P, et al. Left ventricular lead electrical delay is a predictor of mortality in patients with cardiac resynchronization therapy. Circ Arrhythmia Electrophysiol. 2015;8: 1113-21. https://doi.org/10.1161/CIRCEP.115. 003004.
50. Steffel J, Rempel H, Breitenstein A, et al. Comprehensive cardiac resynchronization therapy optimization in the real world. Cardiol J. 2014;21: 316-24.

51. Ellenbogen KA, Gold MR, Meyer TE, et al. Primary results from the SmartDelay determined AV optimization: a comparison to other AV delay methods used in cardiac resynchronization therapy (SMARTAV) trial: a randomized trial comparing empirical, echocardiography-guided, and algorithmic atrioventricular delay programming in cardiac resynchronization therapy. Circulation. 2010;122: 2660-8.

52. Martin DO, Lemke B, Birnie D, et al. Investigation of a novel algorithm for synchronized left-ventricular pacing and ambulatory optimization of cardiac resynchronization therapy: results of the adaptive CRT trial. Heart Rhythm. 2012;9:1807-14. https:// doi.org/10.1016/j.hrthm.2012.07.009.

53. Singh JP, Abraham WT, Chung ES, et al. Clinical response with adaptive CRT algorithm compared with CRT with echocardiography-optimized atrioventricular delay: a retrospective analysis of multicentre trials. Europace. 2013;15:1622-8. https:// doi.org/10.1093/europace/eut107.

54. Varma N, O'Donnell D, Bassiouny M, et al. Programming cardiac resynchronization therapy for electrical synchrony: reaching beyond left bundle branch block and left ventricular activation delay. J Am Heart Assoc. 2018; 7:e007489.

55. Abdelrahman M, Subzposh FA, Beer D, et al. Clinical outcomes of his bundle pacing compared to right ventricular pacing. J Am Coll Cardiol. 2018;71:2319-30. https://doi.org/10.1016/j.jacc. 2018.02.048.

56. Lewis AJM, Foley P, Whinnett Z, Keene D, Chandrasekaran B. His bundle pacing: a new strategy for physiological ventricular activation. J Am Heart Assoc. 2019;8:e010972. https://doi.org/10.1161/ JAHA.118.010972.

57. Upadhyay GA, Vijayaraman P, Nayak HM, et al. Ontreatment comparison between corrective His bundle pacing and biventricular pacing for cardiac resynchronization: a secondary analysis of the HisSYNC Pilot Trial. Heart Rhythm. 2019;16(12): 1797-807. https://doi.org/10.1016/j.hrthm.2019. 05.009.

58. Spartalis M, Iliopoulos DC, Spartalis E, et al. Is the clinical benefit of implantable cardioverter-defibrillators in heart failure patients declining? J Cardiol. 2020;75(5):583-4. https://doi.org/10.1016/j. jjcc.2020.02.002. 
59. Spartalis M, Iliopoulos DC, Spartalis E, et al. The genesis of ventricular arrhythmias in heart failure patients is based on alterations in cardiac mechanical, morphological, metabolic, electrophysiological properties, and neurohumoral remodeling. J Cardiol. 2020;76(3):322-3. https://doi.org/10. 1016/j.jjcc.2020.03.005.

60. Kontogiannis C, Tampakis K, Georgiopoulos G, et al. Electrical Storm: current evidence, clinical implications, and future perspectives. Curr Cardiol Rep. 2019;21(9):96. https://doi.org/10.1007/ s11886-019-1190-0.
61. Hussein AA, Wilkoff BL. Cardiac implantable electronic device therapy in heart failure. Circ Res. 2019;124(11):1584-97. CIRCRESAHA.118.313571.

62. Slotwiner D, Varma N, Akar JG, et al. HRS expert consensus statement on remote interrogation and monitoring for cardiovascular implantable electronic devices. Heart Rhythm. 2015;12(7):e69-100. https://doi.org/10.1016/j.hrthm.2015.05.008. 